\title{
TOTAL PHENOLIC CONTENT AND ANTIRADICAL ACTIVITY OF HONEY POWDERS
}

\author{
*Anete Keke, Ingmars Cinkmanis \\ Latvia University of Life Sciences and Technologies, Latvia \\ *Corresponding author's email: anete.keke@llu.lv
}

\begin{abstract}
Honey powders could be an innovative and attractive substitutes to liquid honey. The production of honey powders would allow to expand honey's usage in food industry, cosmetics and pharmaceutics. In this research, freeze drying method was performed to obtain honey powder samples. Overall, 4 different formulations were prepared to obtain the powder samples. The aim of the research was to determine the total phenolic content and antiradical activity of the freeze-dried honey powder samples by spectrophotometric method. The content of total phenolics in the samples ranged from 92 to $146 \mathrm{mg} \mathrm{GAE} 100 \mathrm{~g} \mathrm{~g}^{-1}$ of dry matter. Antiradical activity was measured with DPPH radical scavengers, and the $\mathrm{IC}_{50}$ results ranged from 6 to $12 \mathrm{mg} \mathrm{mL}^{-1}$.
\end{abstract}

Key words: honey powder, freeze drying, antiradical activity, total phenolic content.

Abbreviations: $\mathrm{H}$, honey; MD, maltodextrin; MN, mannitol; DPPH, 2,2-diphenyl-1-picryhydrazyl; $\mathrm{IC}_{50}$, half maximal inhibitory concentration; AA, antiradical activity; GAE, gallic acid equivalent.

\section{Introduction}

Honey is a naturally sweet food stuff, which has high nutritional value and it's therapeutic properties are well-known over the centuries. Honey consists of 200 chemical compounds (Bueno-Costa et al., 2016). The wide range of different substances are found in honey such as enzymes, amino acids, organic acids, monosaccharides, different phenolic compounds (Tezcan et al., 2011; Da Silva et al., 2016). Noteworthy that the chemical profile of honey depends on many factors, for instance, climate, botanical and geographical origin. Honey is classified in different types, which are based on their geographical origin or floral source (Sakač et al., 2018). The phenolic profile of honey is mostly the same, but the concentrations of phenolic compounds in different type are variant (Badolato et al., 2017). Phenolic compounds such as phenolic acids and flavonoids are natural antioxidants (da Silva et al., 2013). Antioxidants have a significant role in human health (Mithul Aravind et al., 2021), they protect the body cells from free radicals. Free radicals are very reactive and have a tendency to react with biomolecules, which could result in serious cell damages (Zheng et al., 2020).

The production of powdered honey is an innovative approach to expand the application of honey in food industry, pharmaceutical industry. Longer shelf life and expanded usage in food processing (Tong et al., 2010; K1lınç \& Demir, 2017; Tomczyk et al., 2020) are a few of advantages of powdered honey, which present powdered honey as an attractive substitute to natural honey. The interest of production of honey powder among food scientists has been increased (Samborska, 2019). Different drying methods (Nurhadi et al., 2012; Sramek et al., 2016; Samborska et al., 2017) have been studied for obtaining honey powder. As honey is a sugar-rich food product (Muzaffar, 2015), its drying is very challenging. The main issue is that sugar-rich food products during drying can make lumps or syrup (Bhandari et al., 1997). This issue mainly can be prevented by adding different drying aids or carriers to increase the glass temperature of drying particles (Shi et al., 2013). Freeze-drying among all drying methods, which are recently performed for obtaining high quality honey powder, is not very common (Ganaie et al., 2021). The main reason of that is a long production time, which expands the cost of production. Nevertheless, freeze-drying is bioactive compounds preserving drying technique (Ranieri et al., 2017; Prosapio \& Norton, 2018).

The phenolic profile of honey and other food products can be evaluated by different analytical techniques (Chan et al., 2013; Zhu et al., 2019; Tian et al., 2021). Spectrophotometric method is one of the most popular analytical methods due to its low cost, simplicity, rapidness. Total phenolics content is commonly determined using Folin-Ciocalteu reagent. The method is easy to modify and allows to detect total phenolic content in a wide range of products (Kek et al., 2014; Paradiso et al., 2016; Hinojosa-Nogueira et al., 2020). Antiradical activity of different food products is examined by the DPPH test (Marinova \& Batchvarov, 2011; Naji et al., 2020).

The production of honey powder involves thermal treatment and could negatively affect the quality of honey by, for example, decreasing enzyme activity (Tosi et al., 2008; Sramek et al., 2016; Samborska et al., 2017), increasing the concentration of 5-hydromethylfurfural (Pasias et al., 2017; Kanar \& Maz1, 2019).

As phenolic compounds are sensitive to temperature changes (Molaveisi et al., 2019; Samborska et al., 2019), it is important to examine honey powder. The aim of the research was to determine the total phenolic content and antiradical activity of the freeze-dried honey powder samples by spectrophotometric method. 


\section{Materials and Methods}

The experimental work of study took place at the Scientific laboratory of Natural compounds at the Department of Chemistry, Faculty of Food Technology, Latvia University of Life Sciences and Technologies.

Buckwheat honey was purchased from a local beekeeper. Buckwheat honey was harvested in 2019. The beehives were placed in Jelgava district, the southern-central part of Latvia.

Maltodextrin (STAR-DRI ${ }^{\circledR} 10$ NG, TALE \& LYLE, USA) was delivered by Latvian company (BANG \& BONSOMER LATVIA, Rīga, Latvia). Dextrose equivalent (DE) of maltodextrin was 10.4. Moisture content, according to the certificate given by the company, was $4.3 \%$. Mannitol was purchased form Riedel-de HaënÔ and moisture content was $0.5 \%$. (Honeywell, Germany).

Freeze-drying of honey solution

Four different $30 \%$ aqueous solutions of honey with mannitol and maltodextrin were prepared for the experiments.

The proportions of honey and carriers in feed solutions are shown in Table 1.

Table 1

Proportion of honey and carrier in feed solution

\begin{tabular}{|l|c|}
\hline \multicolumn{1}{|c|}{ Carrier } & Ratio (honey: carrier) \\
\hline Mannitol & $1: 1$ \\
\hline Maltodextrin & $1: 1$ \\
\hline Mannitol & $1: 2$ \\
\hline Maltodextrin & $1: 2$ \\
\hline
\end{tabular}

The solutions were poured into plastic freezer containers. The height of solution layer in each container was approximately one centimetre. The containers were kept in the freezer at $-20 \pm 1{ }^{\circ} \mathrm{C}$ for 3 hours. Drying of frozen samples were performed as described by Keke (Keke \& Cinkmanis, 2020). The obtained freeze-dried honey samples each were grinded into powder by porcelain mortar and pestle. The powder samples were collected in polyethylene bags and stored at $+20^{\circ} \mathrm{C}$ temperature in dark and dry place until further analysis.

\section{Detection of moisture content}

Determination of moisture content was carried out using a moisture analyzer AND MX-50 (A\&D Company, Limited, Japan). The moisture content of samples were evaluated using the method described by Keke (Keke \& Cinkmanis, 2020). The software 'WinCT-Moisture' was used for the data recording. Detection of total phenolics

The content of total phenolics of the obtained honey powders and buckwheat honey were evaluated by the Folin-Ciocalteu method. The honey powder samples and honey were dissolved in deionized water. The concentration of each prepared solutions was $0.1 \mathrm{~g} \mathrm{~mL}^{-1}$. Then $2.5 \mathrm{~mL}$ of $0.2 \mathrm{M}$ Folin-Ciocalteu reagent (Sigma Aldrich $\AA$, Germany) were added to $0.5 \mathrm{~mL}$ of prepared solutions and mixed. After 5 minutes $2 \mathrm{~mL}$ of $7.5 \% \mathrm{Na}_{2} \mathrm{CO}_{3}$ solution were added to the mixture and mixed together. The reaction solution was stored at $+20{ }^{\circ} \mathrm{C}$ temperature in the dark for 2 hours. After incubation the content of total phenolics was determined by spectrophotometer Jenway 6405 UV/Vis (JENWAY, the U.K.). The absorbance of the samples was measured at $760 \mathrm{~nm}$. Deionized water was used as blank solution. The results were expressed as gallic acid equivalents mg GAE $100 \mathrm{~g}^{-1}$ dry matter (Cinkmanis, Dimins, \& Mikelsone, 2017).

Detection of antiradical activity

The antiradical activity of the samples was determined using 2,2-diphenyl-1-picrylhydrazyl radical (DPPH). The obtained powders and buckwheat honey were dissolved in deionized water at concentrations ranging from 2 to $14 \mathrm{mg} \mathrm{mL}^{-1}$. And $3.5 \mathrm{~mL}$ of prepared solution was well-mixed with 1.5 $\mathrm{mL}$ of $0.1 \mathrm{mM}$ DPPH (Sigma Aldrich ${ }^{\circledR}$, Germany) solution. The reaction solution was stored at +20 ${ }^{\circ} \mathrm{C}$ temperature in the dark for 30 minutes. After incubation the determination of antiradical activity was performed by spectrophotometer Jenway 6405 UV/Vis (JENWAY, the U.K.). The absorbance of the samples was measured at $515 \mathrm{~nm}$. The results were expressed as the percentage of antiradical activity (AA). The antioxidant activity was calculated according to the following formula:

$$
A A=\left(\frac{A B S_{\text {control }}-A B S_{\text {sample }}}{A B S_{\text {control }}}\right) \times 100
$$

As blank solution, dissolved honey powder solutions at the same concentrations as previously were described and $3.5 \mathrm{~mL}$ of methanol were used. The control solution consisted of $3.5 \mathrm{~mL}$ of methanol (Sharlab S.L., Spain) and $1.5 \mathrm{~mL}$ of $0.1 \mathrm{mM} \mathrm{DPPH}$ solution. The $\mathrm{IC}_{50}$ values were calculated by linear regression of plots, where the concentration of prepared solutions were represented on the abscissa, and the antiradical activity of prepared solutions was represented on the ordinate (Pontis et al., 2014; Cinkmanis, Dimins, \& Mikelsone, 2017).

\section{Statistical analysis}

The assays were repeated three times, and the results were expressed as mean values \pm standard deviation (SD).

One-way analysis of variance (ANOVA) and Tukey's test $(p<0.05)$ were used to verify statistical differences. Analysis were performed by Microsoft 365 Excel. 
Moisture content and $\mathrm{IC}_{50}$ value in the analysed samples

\begin{tabular}{|l|c|c|c|}
\hline \multicolumn{1}{|c|}{ Carrier } & Ratio (honey: carrier) & Moisture content, $\%$ & $\mathrm{IC}_{50}, \mathrm{mg} \mathrm{mL}^{-1}$ \\
\hline \multirow{2}{*}{ Mannitol } & $1: 1$ & $4.5 \pm 0.2$ & $6 \pm 1$ \\
\cline { 2 - 4 } & $1: 2$ & $3.5 \pm 0.2$ & $8 \pm 2$ \\
\hline \multirow{2}{*}{ Maltodextrin } & $1: 1$ & $5.6 \pm 0.1$ & $10 \pm 1$ \\
\cline { 2 - 4 } & $1: 2$ & $3.3 \pm 0.2$ & $12 \pm 1$ \\
\hline
\end{tabular}

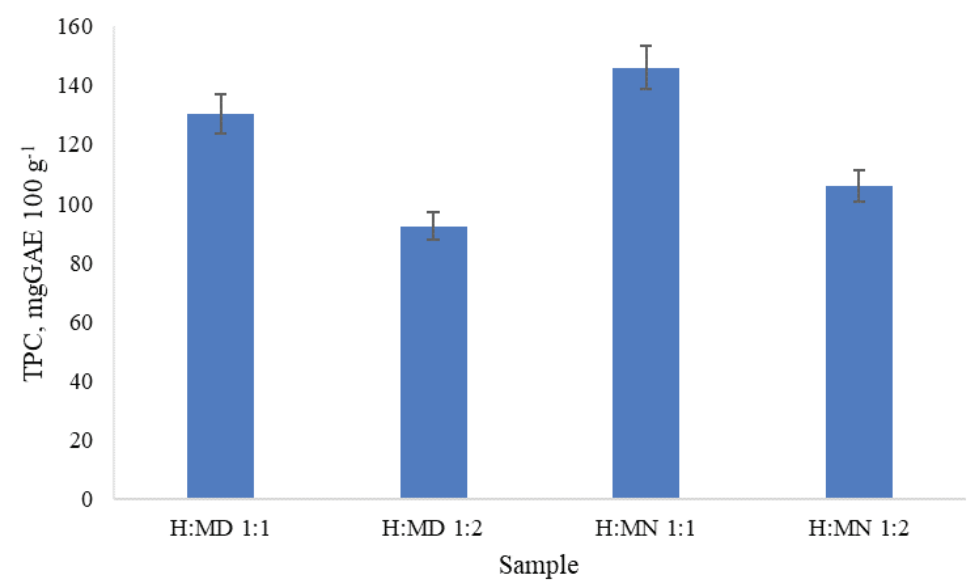

Figure 1. Total phenolic content in honey: maltodextrin 1:1 (H:MD 1:1), honey: maltodextrin 1:2 (H:MD 1:2), honey: mannitol 1:1 (H:MN 1:1), honey: mannitol 1:2 (H:MN 1:2) powder samples.

\section{Results and Discussion}

Freeze-drying method was performed to obtain honey powder samples. This dehydration technique is well-known in pharmaceutics as bioactive compounds preserving drying method (Scutellà et al., 2018). Overall, four formulations were prepared to obtain honey powders. The moisture content in the samples varied from 3.3 to $5.6 \%$. The moisture content in each analysed sample is shown in Table 2 .

Maltodextrin and mannitol both are widely used carriers. Maltodextrin is commonly used for drying experiments in food industry (Siccama et al., 2021; Teo et al., 2021). It is usually added during spray drying process to increase the glass transition temperature of drying agent (Hebbar, Rastogi \& Subramanian, 2008). Mannitol is a popular non-hygroscopic additive in freeze-drying formulations for pharmaceutical experiments (Kaialy \& Nokhodchi, 2015). Mannitol is sugar alcohol, which is used for providing a stable matrix structure during freeze-drying (Mehta et al., 2013).

Total phenolic content in the freeze-dried honey powder samples and fresh buckwheat honey was determined by Folin-Ciocalteu method. The method is based on the reaction between the Folin-Ciocalteu reagent and phenolic compounds, which forms a coloured complex. Spectrophotometric method was used to measure the absorbance of coloured complex. The measured absorbance data was used to quantify total phenolic content in the samples. The total phenolic content of the samples ranged from 92 to 146 mg GAE $100 \mathrm{~g}^{-1}$ dry matter. High concentrations of phenolics were detected in the samples, where the ratio of honey and carrier was 1:1 (Figure 1). The sample, which contained mannitol, showed the highest content of total phenolics.

Difference in the content of total phenolic compounds in the samples, where the proportion of honey and carrier was 1:2, was not statistically significant $(\mathrm{p}>0.05)$. Total phenolic content was analysed in buckwheat honey, which was used for drying experiments. The content of total phenolic in the honey sample was $175 \mathrm{mg}$ GAE $100 \mathrm{~g}^{-1}$ dry matter. Statistically the difference in values between buckwheat honey and obtained dry food products was not significant $(\mathrm{p}>0.05)$. Samborska and co-workers (Samborska et al., 2019) also used maltodextrin as carrier in their spray drying experiments to obtain honey powder. In the research, the scientists used different formulations of rapeseed honey and maltodextrin. The highest content of total phenolics was detected in the sample, where honey and maltodextrin ratio was 
80:20. In their case, spray drying with dehumidified air was performed to obtain honey powder. The determined value of total phenolics was $78.5 \pm 3.7 \mathrm{mg}$ GAE $100 \mathrm{~g}^{-1}$ dry matter (Samborska et al., 2019).

Antiradical activity was examined using 2,2-diphenyl-1-picrylhydrazyl (DPPH) reagent, which in reaction with antioxidants forms a yellow solution, which is the colour of the reduced form of DPPH. The absorbance of the coloured solutions were measured and used to determine the antiradical activity of analysed samples. The antiradical activity of the analysed samples were expressed as $\mathrm{IC}_{50}$ value. The $\mathrm{IC}_{50}$ value shows the ability of sample to inhibit $50 \%$ of free radicals. The lower $\mathrm{IC}_{50}$ value of the sample is detected, the greater ability it has to neutralize free radicals. The obtained $\mathrm{IC}_{50}$ values ranged from 6 to $12 \mathrm{mg} \mathrm{mL}^{-1}$ (Table 2). The powders, which contained mannitol, showed the lowest $\mathrm{IC}_{50}$ values, and they had a greater ability to neutralize free radicals than the powders, which contained maltodextrin. The reason, why mannitol showed a greater ability to neutralize DPPH, is that mannitol also has antioxidant properties (den Hartog et al., 2010). The $\mathrm{IC}_{50}$ value of used buckwheat honey was $3 \pm 2 \mathrm{mg} \mathrm{mL}^{-1}$. Comparing both used carriers and their influence to antiradical activity in powders, maltodextrin showed statistically significant influence to the antiradical activity $(\mathrm{p}<0.05)$, but mannitol's influence was not statistically significant $(\mathrm{p}>0.05)$.

The freeze-drying process involves very low temperatures and pressure, which allow to protect temperature sensitive phenolic compounds from degradation (Kaialy \& Nokhodchi, 2015). As honey is a hygroscopic food product, it is difficult to obtain dehydrated honey without adding carrier materials (Ganaie et al., 2021). Obtaining dehydrated honey samples by this method was not time efficient and should be modified to optimize drying time and increase the content of honey. Unfortunately, to authors' knowledge there are not scientific publications on obtaining honey powder, where mannitol would be used as a carrier. The experiments showed that mannitol could be used as carrier material for food drying experiments. The application of mannitol as a carrier material in drying experiments might be limited due to its laxative effect. The laxative effect of mannitol might be observed if the daily intake of mannitol exceeds $20 \mathrm{~g}$ (Grembecka, 2015). There are many studies (Mooradian et al., 2017; Sahin et al., 2018), where mannitol and other sugar alcohols have been investigated and considered as sucrose substitutes. Honey powder is a relatively new food product, which still needs to be investigated. The further investigations of honey powder would allow to present it to food consumers as an innovative and examined dry food product.

\section{Conclusions}

Freeze-drying could be applied as an alternative dehydrating method for obtaining honey-rich powder. Total phenolic content and antiradical activity in the prepared honey powders depend on honey content in the experimental formulations. The obtained powdered samples, which contained honey and mannitol, showed the highest content of total phenolic compounds than the samples, which contained honey and maltodextrin at the same ratio.

\section{Acknowledgements}

This study was financially supported by the Latvia University of Life Sciences and Technologies' project "Strengthening Research Capacity in the Latvia University of Life Sciences and Technologies". Project No. 3.2-10/2019/LLU/140.

\section{References}

Badolato, M., Carullo, G., Cione, E., Aiello, F., \& Caroleo, M.C. (2017). From the hive: Honey, a novel weapon against cancer. European Journal of Medicinal Chemistry, 142, 290-299. DOI: 10.1016/j. ejmech.2017.07.064.

Bhandari, B.R., Datta, N., \& Howes, T. (1997). Problems associated with spray drying of sugar-rich foods. Drying Technology, 15(2), 671-684. DOI: 10.1080/07373939708917253.

Bueno-Costa, F.M., Zambiazi, R.C., Bohmer, B.W., Chaves, F.C., Silva, W.P. da, Zanusso, J.T., \& Dutra, I. (2016). Antibacterial and antioxidant activity of honeys from the state of Rio Grande do Sul, Brazil. $L W T$ - Food Science and Technology, 65, 333-340. DOI: 10.1016/j.lwt.2015.08.018.

Chan, C.W., Deadman, B.J., Manley-Harris, M., Wilkins, A.L., Alber, D.G., \& Harry, E. (2013). Analysis of the flavonoid component of bioactive New Zealand mānuka (Leptospermum scoparium) honey and the isolation, characterisation and synthesis of an unusual pyrrole. Food Chemistry, 141(3), 1772-1781. DOI: 10.1016/j.foodchem.2013.04.092.

Cinkmanis, I., Dimins, F., \& Mikelsone, V. (2017). Influence of Lyophilization and convective type drying on antioxidant properties, total phenols and flavonoids in pollens. In FOODBALT 2017, 27-28 April (pp. 201-203). Jelgava, Latvia: LLU, Faculty of Food Technology DOI: 10.22616/foodbalt.2017.038.

da Silva, I.A.A., da Silva, T.M.S., Camara, C.A., Queiroz, N., Magnani, M., de Novais, J.S., Soledade, L.E.B., Lima, E. de O., de Souza, A.L., \& de Souza, A.G. (2013). Phenolic profile, antioxidant activity and 
palynological analysis of stingless bee honey from Amazonas, Northern Brazil. Food Chemistry, 141(4), 3552-3558. DOI: 10.1016/j.foodchem.2013.06.072.

Da Silva, P.M., Gauche, C., Gonzaga, L.V., Costa, A.C.O., \& Fett, R. (2016). Honey: Chemical composition, stability and authenticity. Food Chemistry, 196, 309-323. DOI: 10.1016/j.foodchem.2015.09.051.

den Hartog, G.J.M., Boots, A.W., Adam-Perrot, A., Brouns, F., Verkooijen, I.W.C.M., Weseler, A.R., Haenen, G.R.M.M., \& Bast, A. (2010). Erythritol is a sweet antioxidant. Nutrition, 26(4), 449-458. DOI: 10.1016/j. nut.2009.05.004.

Ganaie, T.A., Masoodi, F.A., Rather, S.A., \& Gani, A. (2021). Exploiting maltodextrin and whey protein isolate macromolecules as carriers for the development of freeze dried honey powder. Carbohydrate Polymer Technologies and Applications, 2(November 2020), 100040. DOI: 10.1016/j.carpta.2021.100040.

Grembecka, M. (2015). Sugar alcohols - their role in the modern world of sweeteners: a review. European Food Research and Technology, 241(1), 1-14. DOI: 10.1007/s00217-015-2437-7.

Hebbar, H.U., Rastogi, N.K., \& Subramanian, R. (2008). Properties of Dried and Intermediate Moisture Honey Products: A Review. International Journal of Food Properties, 11(4), 804-819. DOI: 10.1080/10942910701624736.

Hinojosa-Nogueira, D., Pérez-Burillo, S., Ángel Rufián-Henares, J., \& Pastoriza de la Cueva, S. (2020). Characterization of rums sold in Spain through their absorption spectra, furans, phenolic compounds and total antioxidant capacity. Food Chemistry, 323(January). DOI: 10.1016/j.foodchem.2020.126829.

Kaialy, W., \& Nokhodchi, A. (2015). Dry powder inhalers: Physicochemical and aerosolization properties of several size-fractions of a promising alterative carrier, freeze-dried mannitol. European Journal of Pharmaceutical Sciences, 68(2015), 56-67. DOI: 10.1016/j.ejps.2014.12.005.

Kanar, Y., \& Mazı, B.G. (2019). HMF formation, diastase activity and proline content changes in bee pollen dried by different drying methods. LWT, 113. DOI: 10.1016/j.lwt.2019.108273.

Kek, S.P., Chin, N.L., Yusof, Y.A., Tan, S.W., \& Chua, L.S. (2014). Total Phenolic Contents and Colour Intensity of Malaysian Honeys from the Apis spp. and Trigona spp. Bees. Agriculture and Agricultural Science Procedia, 2, 150-155. DOI: 10.1016/j.aaspro.2014.11.022.

Keke, A., \& Cinkmanis, I. (2020). Changes in $\alpha$-amylase activity in honey during the freeze-drying process. Agronomy Research, 18(Special Issue 3), 1717-1726. DOI: 10.15159/AR.20.042.

Kılınç, M., \& Demir, K.M. (2017). The Facilities of Spray Dried Honey Powder Use As a Substitute for Sugar in Cookie Production. Journal of Food and Health Science, 3(2), 67-74. DOI: 10.3153/JFHS17009.

Marinova, G., \& Batchvarov, V. (2011). Evaluation of the methods for determination of the free radical scavenging activity by DPPH. Bulgarian Journal of Agricultural Science, 17(1), 11-24.

Mehta, M., Bhardwaj, S.P., \& Suryanarayanan, R. (2013). Controlling the physical form of mannitol in freeze-dried systems. European Journal of Pharmaceutics and Biopharmaceutics, 85(2), 207-213. DOI: 10.1016/j.ejpb.2013.04.010.

Mithul Aravind, S., Wichienchot, S., Tsao, R., Ramakrishnan, S., \& Chakkaravarthi, S. (2021). Role of dietary polyphenols on gut microbiota, their metabolites and health benefits. Food Research International, 142(October 2020), 110189. DOI: 10.1016/j.foodres.2021.110189.

Molaveisi, M., Beigbabaei, A., Akbari, E., Noghabi, M.S., \& Mohamadi, M. (2019). Kinetics of temperature effect on antioxidant activity, phenolic compounds and color of Iranian jujube honey. Heliyon, 5(1), e01129. DOI: 10.1016/j.heliyon.2019.e01129.

Mooradian, A.D., Smith, M., \& Tokuda, M. (2017). The role of artificial and natural sweeteners in reducing the consumption of table sugar: A narrative review. Clinical Nutrition ESPEN, 18, 1-8. DOI: 10.1016/j. clnesp.2017.01.004.

Muzaffar, K. (2015). Stickiness Problem Associated with Spray Drying of Sugar and Acid Rich Foods: A Mini Review. Journal of Nutrition \& Food Sciences, s12(August), 10-13. DOI: 10.4172/2155-9600.s12-003.

Naji, K.M., Thamer, F.H., Numan, A.A., Dauqan, E.M., Alshaibi, Y.M., \& D'souza, M.R. (2020). Ferricbipyridine assay: A novel spectrophotometric method for measurement of antioxidant capacity. Heliyon, 6(1), e03162. DOI: 10.1016/j.heliyon.2020.e03162.

Nurhadi, B., Andoyo, R., Mahani, \& Indiarto, R. (2012). Study the properties of honey powder produced from spray drying and vacuum drying method. International Food Research Journal, 19(3), 907-912. DOI: $10.1093 / \mathrm{jeg} / 4.2 .219$

Paradiso, V.M., Clemente, A., Summo, C., Pasqualone, A., \& Caponio, F. (2016). Towards green analysis of virgin olive oil phenolic compounds: Extraction by a natural deep eutectic solvent and direct spectrophotometric detection. Food Chemistry, 212, 43-47. DOI: 10.1016/j.foodchem.2016.05.082. 
Pasias, I.N., Kiriakou, I.K., \& Proestos, C. (2017). HMF and diastase activity in honeys: A fully validated approach and a chemometric analysis for identification of honey freshness and adulteration. Food Chemistry, 229, 425-431. DOI: 10.1016/j.foodchem.2017.02.084.

Pontis, J.A., Costa, L.A.M.A. da, Silva, S.J.R. da, \& Flach, A. (2014). Color, phenolic and flavonoid content, and antioxidant activity of honey from Roraima, Brazil. Food Science and Technology (Campinas), 34(1), 69-73. DOI: 10.1590/S0101-20612014005000015.

Prosapio, V., \& Norton, I. (2018). Simultaneous application of ultrasounds and firming agents to improve the quality properties of osmotic + freeze-dried foods. Lwt, 96(March), 402-410. DOI: 10.1016/j. lwt.2018.05.068.

Ranieri, A., Benelli, G., Castagna, A., Sgherri, C., Signorini, F., Bientinesi, M., Nicolella, C., \& Canale, A. (2017). Freeze-drying duration influences the amino acid and rutin content in honeybee-collected chestnut pollen. Saudi Journal of Biological Sciences, 8-11. DOI: 10.1016/j.sjbs.2017.08.011.

Sahin, A.W., Axel, C., Zannini, E., \& Arendt, E.K. (2018). Xylitol, mannitol and maltitol as potential sucrose replacers in burger buns. Food and Function, 9(4), 2201-2212. DOI: 10.1039/c8fo00066b.

Sakač, M.B., Jovanov, P.T., Marić, A.Z., Pezo, L.L., Kevrešan, Ž.S., Novaković, A.R., \& Nedeljković, N.M. (2018). Physicochemical properties and mineral content of honey samples from Vojvodina (Republic of Serbia). Food Chemistry, 276, 15-21. DOI: 10.1016/j.foodchem.2018.09.149.

Samborska, K. (2019). Powdered honey - drying methods and parameters, types of carriers and drying aids, physicochemical properties and storage stability. Trends in Food Science and Technology, 88(May 2017), 133-142. DOI: 10.1016/j.tifs.2019.03.019.

Samborska, K., Jedlińska, A., Wiktor, A., Derewiaka, D., Wołosiak, R., Matwijczuk, A., Jamróz, W., Skwarczyńska-Maj, K., Kiełczewski, D., Błażowski, Ł., Tułodziecki, M., \& Witrowa-Rajchert, D. (2019). The Effect of Low-Temperature Spray Drying with Dehumidified Air on Phenolic Compounds, Antioxidant Activity, and Aroma Compounds of Rapeseed Honey Powders. Food and Bioprocess Technology, 919932. DOI: 10.1007/s11947-019-02260-8.

Samborska, K., Sokołowska, P., \& Szulc, K. (2017). Diafiltration and agglomeration as methods to improve the properties of honey powder obtained by spray drying. Innovative Food Science and Emerging Technologies, 39, 33-41. DOI: 10.1016/j.ifset.2016.10.002.

Samborska, K., Wasilewska, A., Gondek, E., Jakubczyk, E., \& Kamińska-Dwórznicka, A. (2017). Diastase Activity Retention and Physical Properties of Honey/Arabic Gum Mixtures after Spray Drying and Storage. International Journal of Food Engineering, 13(6). DOI: 10.1515/ijfe-2016-0320.

Scutellà, B., Trelea, I.C., Bourlès, E., Fonseca, F., \& Passot, S. (2018). Determination of the dried product resistance variability and its influence on the product temperature in pharmaceutical freeze-drying. European Journal of Pharmaceutics and Biopharmaceutics, 128(May), 379-388. DOI; 10.1016/j.ejpb.2018.05.004.

Shi, Q., Fang, Z., \& Bhandari, B. (2013). Effect of Addition of Whey Protein Isolate on Spray-Drying Behavior of Honey with Maltodextrin as a Carrier Material. Drying Technology, 31(13-14), 1681-1692. DOI: 10.1080/07373937.2013.783593.

Siccama, J.W., Pegiou, E., Zhang, L., Mumm, R., Hall, R.D., Boom, R.M., \& Schutyser, M.A.I. (2021). Maltodextrin improves physical properties and volatile compound retention of spray-dried asparagus concentrate. Lwt, 142(December 2020), 111058. DOI: 10.1016/j.lwt.2021.111058.

Sramek, M., Woerz, B., Horn, H., Weiss, J., \& Kohlus, R. (2016). Preparation of High-Grade Powders from Honey-Glucose Syrup Formulations by Vacuum Foam-Drying Method. Journal of Food Processing and Preservation, 40(4), 790-797. DOI: 10.1111/jfpp.12660.

Teo, A., Lam, Y., Lee, S.J., \& Goh, K.K.T. (2021). Spray drying of whey protein stabilized nanoemulsions containing different wall materials - maltodextrin or trehalose. Lwt, 136(P2), 110344. DOI: 10.1016/j. lwt.2020.110344.

Tezcan, F., Kolayli, S., Ulusoy, H.S.E., \& Erim, F.B. (2011). Evaluation of organic acid, saccharide composition and antioxidant properties of some authentic Turkish honeys. Journal of Food and Nutrition Research, 50(1), 33-40.

Tian, W., Chen, G., Zhang, G., Wang, D., Tilley, M., \& Li, Y. (2021). Rapid determination of total phenolic content of whole wheat flour using near-infrared spectroscopy and chemometrics. Food Chemistry, 344(September 2020), 128633. DOI: 10.1016/j.foodchem.2020.128633.

Tomczyk, M., Zaguła, G., \& Dżugan, M. (2020). A simple method of enrichment of honey powder with phytochemicals and its potential application in isotonic drink industry. Lwt, 125(September 2019). DOI: 10.1016/j.lwt.2020.109204. 
Tong, Q., Zhang, X., Wu, F., Tong, J., Zhang, P., \& Zhang, J. (2010). Effect of honey powder on dough rheology and bread quality. Food Research International, 43(9), 2284-2288. DOI: 10.1016/j.foodres.2010.08.002.

Tosi, E., Martinet, R., Ortega, M., Lucero, H., \& Ré, E. (2008). Honey diastase activity modified by heating. Food Chemistry, 106(3), 883-887. DOI: 10.1016/j.foodchem.2007.04.025.

Zheng, Y.Z., Fu, Z.M., Deng, G., Guo, R., \& Chen, D.F. (2020). Role of C-H bond in the antioxidant activities of rooperol and its derivatives: A DFT study. Phytochemistry, 178(July), 112454. DOI: 10.1016/j. phytochem.2020.112454.

Zhu, Z., Zhang, Y., Wang, J., Li, X., Wang, W., \& Huang, Z. (2019). Sugaring-out assisted liquid-liquid extraction coupled with high performance liquid chromatography-electrochemical detection for the determination of 17 phenolic compounds in honey. Journal of Chromatography A, 1601, 104-114. DOI: 10.1016/j. chroma.2019.06.023. 